\title{
Jean-Philippe Warren \\ Une douce anarchie. Les années 68 au Québec.
}

Montréal : Boréal, 2008, 309 pages.

\section{Karine Hébert}

Université du Québec à Rimouski

Les décennies passant, les années 68 sont devenues mythiques. Or, le mythe se construit souvent sur la tradition orale et le souvenir. Une douce anarchie fait entrer le mythe dans la "science " et pose un regard critique sur le discours révolutionnaire de cette période, étonnamment peu étudiée de l'histoire québécoise récente. Les mouvements étudiants et de jeunesse des années précédant la Révolution tranquille ont récemment fait l'objet de quelques monographies (Neatby, Bienvenue, Hébert, Gauvreau), mais ces travaux visaient en partie à démentir l'assertion voulant qu'avant '68 point de salut. Or depuis que Ricard s'est penché sur la " génération peu lyrique » et que Bédard a examiné les liens entre les mouvements étudiants et le FLQ, des recherches ont été entreprises au sujet de la jeunesse des baby-boomers et encore moins se sont attardées aux mouvements de révolte et de grève de ces années chaudes.

Jean-Philippe Warren fait donc œuvre utile avec cet ouvrage qui trace l'histoire des années préparant les éclats de cette année phare et de celles marquant la chute des idées révolutionnaires et anarchistes qui l'ont portée. La structure essentiellement chronologique de l'ouvrage sert bien la démonstration, permettant au lecteur de voir les montées en tension, et à l'auteur d'insérer une analyse serrée des idées véhiculées par les mouvements étudiants. Les baby-boomers qui ont déjà cru à l'utopie libertaire fondatrice de cette époque tiqueront peut-être à lire " quand on est sans famille, il est facile de proposer l'amour libre pour tout le monde; quand on est aux études, il est facile de dénoncer le travail ; quand on est sans responsabilités, il est facile d'exiger une liberté radicale ». (p. 127) Mais force est d'admettre que Warren propose une lecture critique qui met bien en perspective le paradoxe entre la volonté de changer le monde de ces jeunes et leur individualisme exacerbé.

Quelques pages sont d'entrée de jeu consacrées à l'histoire des associations étudiantes de la province ainsi qu'à la montée du syndicalisme étudiant et du principe 
de cogestion en ces temps de réforme inaugurés par l'arrivée au pouvoir du gouvernement Lesage. Si plusieurs éléments contextuels sont pertinemment soulevés par Warren, entre autres l'arrivée dans les collèges et les universités de l'imposante génération de l'après-guerre, quelques aspects de l'analyse auraient mérité un peu plus de développement. En effet, le syndicalisme étudiant et l'étiquette de travailleur intellectuel n'apparaissent pas dans le discours en 1961. Dès l'après-guerre, et plus particulièrement au cours des années cinquante, les étudiants de l'Université de Montréal ont fait référence à la Charte de Grenoble de Union générale des étudiants français pour tenter d'imposer l'idée d'un syndicalisme étudiant visant à défendre les intérêts des jeunes travailleurs intellectuels qu'ils affirmaient être. Certains commencent à réclamer un siège au bureau des gouverneurs au nom des droits de scolarités qu'ils doivent payer. Le principe de cogestion n'est pas encore ouvertement formulé, mais les bases conceptuelles qui le rendront possible sont déjà bien en place.

La suite de l'ouvrage serre de plus près le cœur du sujet. On voit à l'œuvre l'écart qui existe entre la majorité des étudiants, plus encline au réformisme, et la minorité agissante et radicale, tentée par l'anarchie et les idées libertaires. Après une brève période durant laquelle la cogestion apparaissait comme possible, l'absence de collaboration véritable des institutions d'enseignement et le retour de l'Union nationale au pouvoir entraînent un mécontentement grandissant. La radicalisation du discours se fait sentir, particulièrement à l'UGEQ où le principe de cogestion cède la place à celui d'autogestion. Puis c'est au tour des étudiants du Québec de faire éclater leur colère en octobre 1968. Le cafouillage associé à la toute récente mise en place des cégeps, le sentiment d'aliénation et de dépossession engendré par l'anonymat de ces grosses " usines à étudiants » accentuent la révolte. Les manifestations deviennent des lieux de rassemblement qui comblent un certain vide culturel. Cependant émerge une des failles du mouvement : la plupart des manifestants sont plus spectateurs qu'acteurs. "Les jeunes peuvent ainsi passer pour marginaux tout en se comportant de manière très grégaire et paraître iconoclastes tout en suivant la mode. " (p. 126). Les idéaux anarchistes ne rejoignent qu'une minorité qui sera vite désillusionnée devant l'essoufflement rapide des grèves et occupations.

Les causes de cet échec relatif sont bien exposées par Warren à la fin du chapitre 5 : " refus de participation des étudiants universitaires, mimétisme idéologique un peu juvénile, indifférence de la majorité silencieuse, domination du courant anarchiste chez les plus radicaux et stratégie efficace de répression ». (p.151) Devant le peu d'empressement de la masse, les radicaux se braquent. Des associations étudiantes se font hara-kiri, les vieilles structures représentatives s'effacent pour faire place à l'action directe et à des appels à la " guérilla scolaire ". L'Opération McGill français et la crise du Bill 63, en 1969, peuvent être considérées comme le point d'orgue de cette logique contestataire. En même temps, l'échec de ces protestations improvisées - la loi 63 ayant quand même été adoptée — souligne l'inefficacité des soulèvements de la base. L'anarchisme ne répond pas aux attentes, et le besoin de voir se développer une organisation structurée refait surface. Le fossé se creuse encore davantage entre les leaders radicaux et la majorité réformiste, la Crise d'octobre 70 marquant la fin de l'idéologie anarchiste des années 1968 au Québec. 
Tout au long de l'ouvrage, Warren prend la peine de faire la part des choses entre le conjoncturel et le structurel, entre le discours et les faits. Soucieux de situer le mouvement étudiant québécois dans un contexte sociopolitique plus large, il tient compte des modifications importantes qui agitent le Québec des années 60 et des influences internationales. Il est particulièrement rafraîchissant de voir la manière dont Warren aborde les contradictions idéologiques du mouvement et fait le bilan du legs de ce temps fort de la contestation étudiante. D'une part, il prend la peine de rappeler que tous ne dansaient pas avec la même frénésie, les meneurs - bien qu'ils aient probablement refusé de porter ce titre — ne formant qu'une minorité. Il montre également qu'en prônant l'absence de règle et de mots d'ordre, l'idéologie libertaire contenait en son sein les germes de son échec, en exacerbant l'individualisme. D'autre part, Warren insiste sur la grande réussite symbolique du mouvement; les années 1968 ont en effet marqué leur époque et ont permis de démontrer qu'il est encore possible aujourd'hui de créer des mythes.

Soulignons pour terminer que l'auteur a su jouer avec son propos : le vocabulaire anarchiste conjugué aux termes savants conduit à une prose parfois déboussolante mais jamais ennuyante. Plusieurs trouveront leur compte à lire Une douce anarchie : anciens militants s'y mireront dans une glace peut-être grossissante mais ô combien révélatrice, historiens et sociologues y puiseront informations et analyses généralement exposées avec clarté, jeunes d'aujourd'hui y découvriront la construction d'un mythe et comprendront, osons l'espérer, qu'ils n'ont rien à envier à la mobilisation de leurs aînés. 